\title{
Strategies for Addressing Inequality in Coastal Settings
}

\author{
Professor Stephen Olsen, Coastal Resources Centre, University of Rhode Island, USA
}

\begin{abstract}
Many coastlines are home to growing populations of poor people. In such places the gap between the rich and the poor is often widening and the resulting inequalities in access to natural resources and political power, combined with few opportunities for personal advancement, are dominant challenges. If we accept that Integrated Coastal Management (ICM) must address both the environmental and the human dimensions of planning and decision making then the complexities of poverty and social inequality need to be a central to the agendas of ICM programs where these conditions prevail. Yet many ICM practitioners are educated as engineers and natural scientists and feel ill prepared to address such issues. Many ICM programs have made environmental and bio-physical issues their focus and done little to address the societal and governance issues that are priority concerns for the people of the place. This paper suggests a set of strategies for making issues of poverty and social inequality central themes in ICM programs. This is essential in settings where constituencies for ICM must built among the poor and disenfranchised. Without the active support of those most dependent upon their immediate surroundings - be they urban or rural - the necessary reforms to coastal planning and decision making will not take root and generate positive outcomes over the long term.
\end{abstract}

